\title{
Structural and historical assessment of a modern heritage masterpiece: "Palazzo del Lavoro" in Turin
}

\author{
S. Sorace ${ }^{1} \&$ G. Terenzi ${ }^{2}$ \\ ${ }^{I}$ Department of Civil Engineering and Architecture, \\ University of Udine, Italy \\ ${ }^{2}$ Department of Civil and Environmental Engineering, \\ University of Florence, Italy
}

\begin{abstract}
A structural and historical assessment study on "Palazzo del Lavoro", a modern heritage building in Turin, designed by Pier Luigi Nervi in 1959, was carried out within a National Research Project focused on the correlations between the leading engineering and architectural activities in Italy during the 1950s and 1960s. Based on the original design documentation collected through records research, a complete finite element model of the building was generated, along with detailed models of its main structural members, represented by monumental reinforced concrete columns, a mushroom-type steel roof, and reinforced concrete ribbed gallery slabs. The results of the linear and non-linear analyses developed by these models, aimed at fully understanding the original design concept of the various members, as well as at evaluating their current static and seismic safety conditions, are summarized in the paper. Retrofit hypotheses are also proposed for the steel roof beams and the cantilever elements of the gallery floors, which did not meet some of the structural requirements.

Keywords: modern architectural heritage, historical research, structural assessment, seismic assessment, linear analysis, non-linear analysis, retrofit.
\end{abstract}

\section{Introduction and historical background}

Nowadays, growing attention is being devoted to the study of modern heritage, and particularly to the edifices built from the aftermath of the Second World War 
until the late Sixties. Indeed, that was a very prolific period for architecture and structural engineering, which produced significant theoretical and technical advancements in both fields. As a consequence, a global enhancement of the construction industry was reached, and a great number of exemplary masterpiece structures were designed and erected worldwide.

This important stock of buildings represents today a significant heritage, which is now over fifty years old, and may require important structural maintenance, repair and/or rehabilitation interventions. In view of this, careful evaluation and verification analysis strategies are needed, so as to check the actual safety conditions of these skilled engineering works, and to plan possible retrofit solutions. At the same time, the development of assessment analyses of these outstanding buildings offers a profitable chance to improve the knowledge on the characteristics of their constituting materials, structural details and construction work procedures, as well as on the calculation methods originally adopted for their design.

An Italian masterpiece belonging to this stock named "Palazzo del Lavoro" in Turin, designed by the world-famous structural engineer Pier Luigi Nervi, is examined in this paper. The building, an external view of which at the time of its opening is shown in Figure 1, constituted the most important exhibition hall erected for the celebrations held in Turin for the first centenary of the Unity of Italy, back in 1961 .

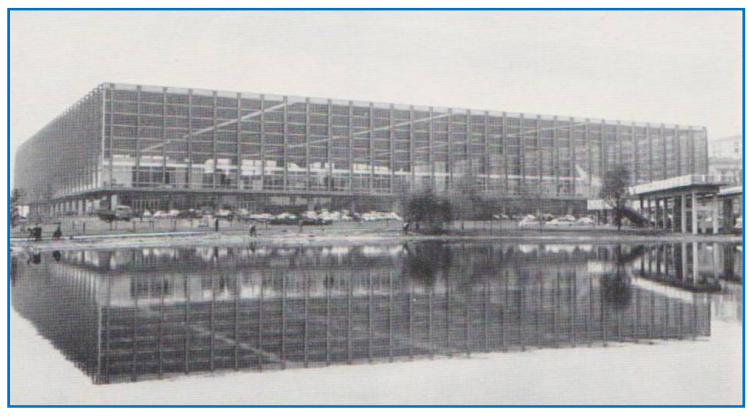

Figure 1: $\quad$ External view of the building at the time of its opening.

The structure was designed in 1959 and completed by the Spring of 1961, after sixteen months only. This represented a really challenging enterprise, which can still arouse admiration, especially when the short construction times are compared to the imposing size of the building $-160 \times 160 \mathrm{~m} \times \mathrm{m}$ in plan - , and considering the strict architectural and functional constraints imposed on the design, e.g. the 40m-long free spans required between each vertical structural element. The solution devised by Nervi consisted in a mesh of sixteen reinforced concrete $(\mathrm{R} / \mathrm{C})$ columns with variable section along the height (equal to $20 \mathrm{~m}$ to the base of the roof), each one supporting a steel mushroom-type roof panel with radial beams spanning from the centre of each column. The panels are mutually separated by a $2 \mathrm{~m}$-wide joint covered by a glass skylight. This solution, 
illustrated by the roof plan in Figure 2, conferred a suggestive monumental aspect to the building. Photographic images taken during the construction works of the $\mathrm{R} / \mathrm{C}$ columns and the steel roof panels are displayed in Figure 3. The final configuration of the interiors in an original view at the conclusion of the works and in a recent view are shown in Figure 4.
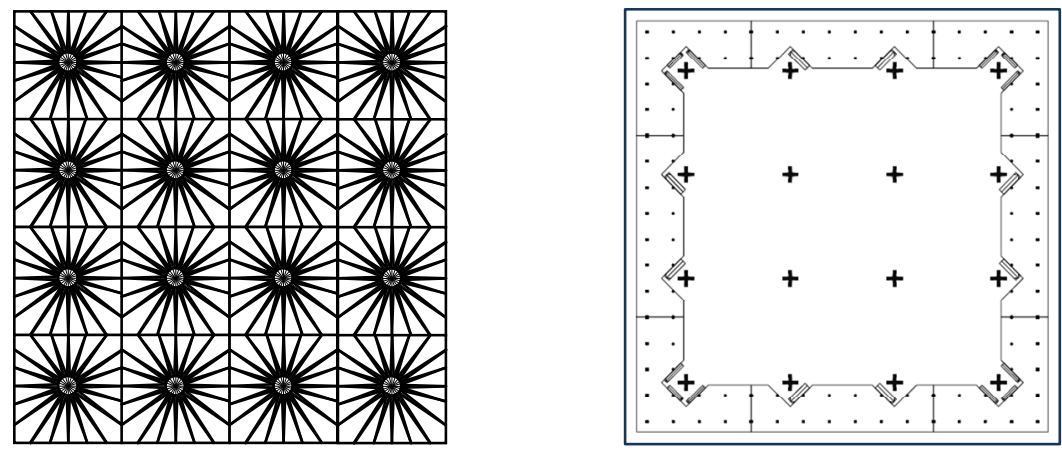

Figure 2: $\quad$ Plans of the roof and the upper gallery.
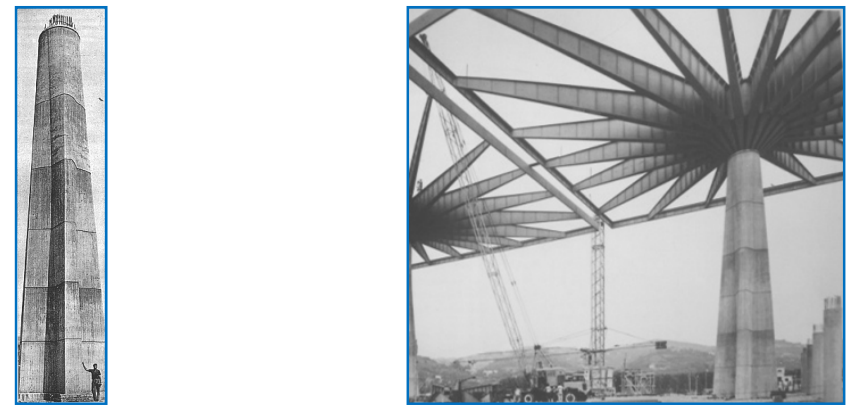

Figure 3: Images of the construction works of the $\mathrm{R} / \mathrm{C}$ columns and the steel roof panels.
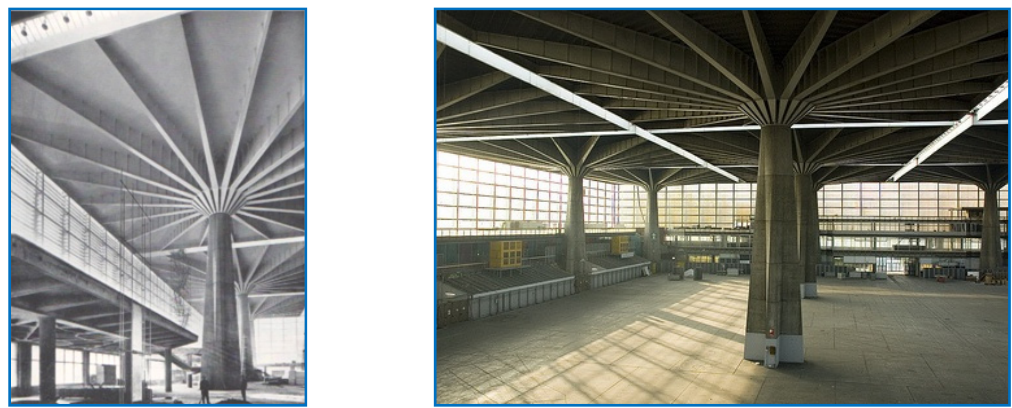

Figure 4: Views of the interiors at the end of the construction works and in recent times. 
The remaining structural elements also remarkably contribute to the elegant and monumental look of the building. The most important of these elements are the $\mathrm{R} / \mathrm{C}$ ribbed slabs constituting the gallery floors. A plan of the upper floor is shown to the right of Figure 2. The design solution for the slabs, traced out following the analytical equal-stress lines of their plate model, is typical of Nervi's style, and was also applied to other prominent structures by the same engineer. Two images of the formworks, specially designed to the purpose, and the installation of the reinforcing bars during the construction works of the slabs are presented in Figures 5. Two views of the intrados of the slabs, with the steel roof in the background, are displayed in Figure 6.
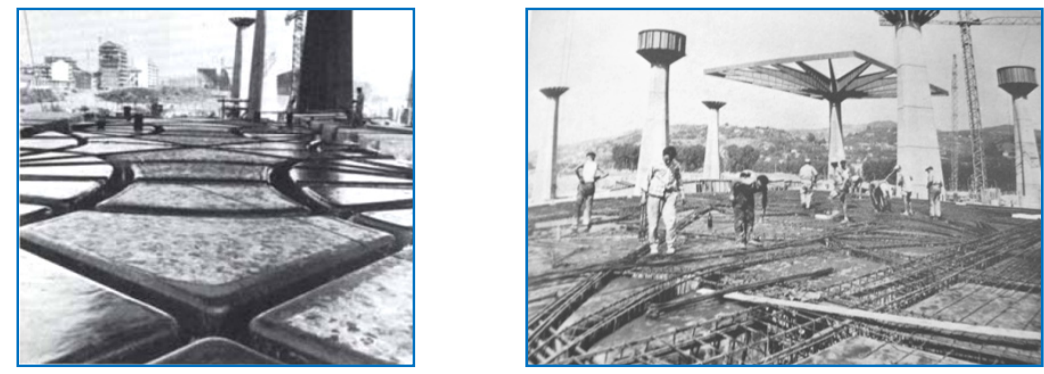

Figure 5: Images of the construction works of the $\mathrm{R} / \mathrm{C}$ ribbed slabs of the gallery floors.
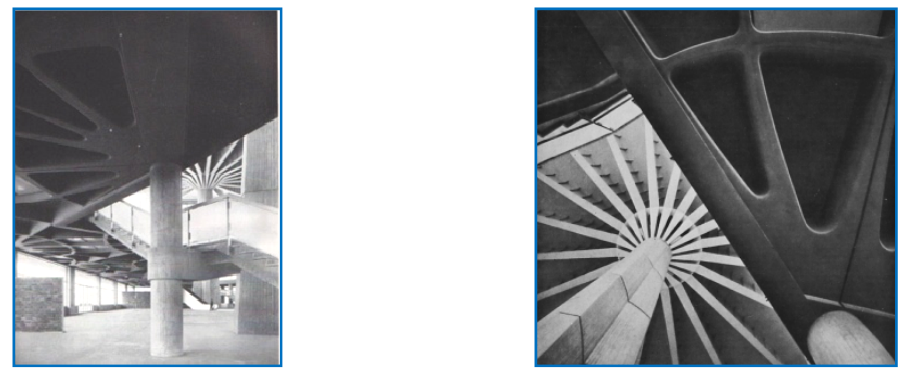

Figure 6: Intrados views of the $\mathrm{R} / \mathrm{C}$ ribbed slabs of the gallery floors.

The paper offers a synthesis of the structural and seismic assessment analyses carried out on the building, as part of the studies developed by the authors within a National Research Project financed by the Italian Ministry of Education, University and Research, dedicated to the innovative structural projects and the correlations between the leading engineering and architectural activities in Italy, during the 1950s and 1960s. The results of the analyses highlight reasonably safe conditions in general, with important exceptions represented by the steel roof beams, which failed to pass the verifications of local panel and global flexuraltorsional buckling, and some cantilever beams of gallery floors, which show poor shear resistance. Retrofit hypotheses are also formulated for these elements, 
so as to help the entire structure comply with the requirements of the new Italian Technical Standards [1].

\section{Modal analysis of the building structure}

The modal analysis of the building was carried out by a complete finite element model, generated by the SAP2000NL calculus program [2], where all the structural elements - continuous gallery-to-roof glass façades and relevant bold bracing systems included-were reproduced. The first two modes are mixed rotational around the vertical axis $\mathrm{z}$ - translational along the two main directions in plan, $\mathrm{x}$ and $\mathrm{y}$. Both modes, whose shapes are plotted in Figure 7, feature a vibration period of $1.36 \mathrm{~s}$, effective masses associated to the relevant translational component equal to around $20.8 \%$ of the total seismic mass of the building, and effective masses associated to the rotational component equal to around $7 \%$.
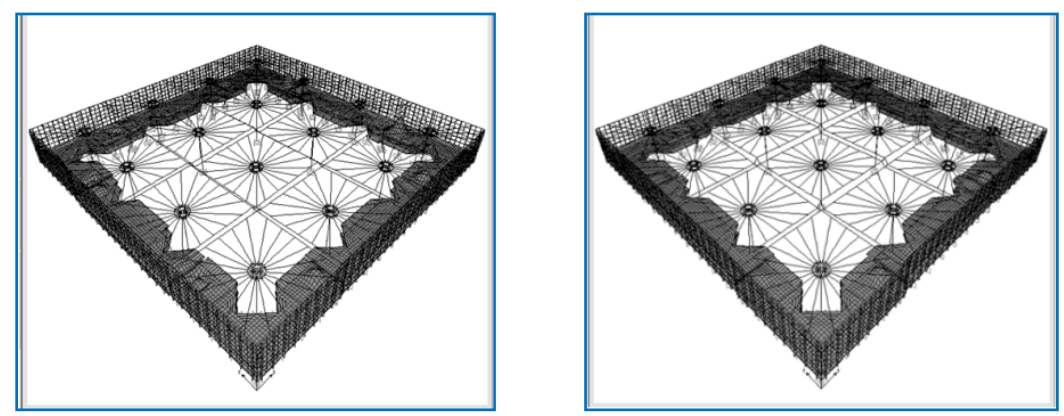

Figure 7: First and second modal shapes of the finite element model of the building.

The first two modal shapes are dominated by the deformation of the sixteen couples of roof panels and relevant supporting columns, which respond in an independent way from each other, as a consequence of the existing separation joints at roof level. Concerning the superior modes, "crowds" of 4 through 6 modes are repeatedly observed in correspondence with specific vibration periods, with negligible associated masses, as these "secondary" modes are essentially related to local response effects. Several dozen modes are required to gradually find significant mass contributions and, in total, 83 modes are needed to activate a summed mass greater than $85 \%$ along the two directions in plan, and around the vertical axis.

\section{Analysis of the monumental $R / C$ columns}

The shape of the monumental columns constantly varies from the base (crosstype section with $6 \mathrm{~m}$-long and $1 \mathrm{~m}$-wide sides) to the top (circular-type section, $2.5 \mathrm{~m}$ wide), as illustrated by the sequence of geometrical cross sections along 
the height reproduced in Figure 8. This variable shape was designed in order to obtain nearly "uniform resistance" members with respect to the combined effects of bending moments and axial force. The top section, reduced to a diameter of 2 $\mathrm{m}$, is prolonged for further $1.6 \mathrm{~m}$ to form the groove where the triangular steel plates supporting the circular drum of the mushroom roof are positioned, as shown to the right of Figure 8.
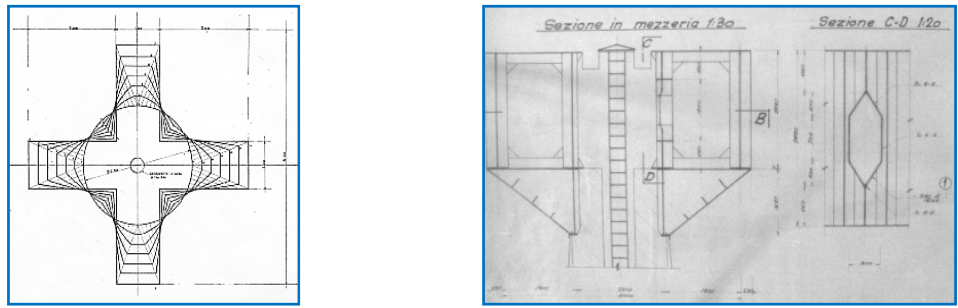

Figure 8: Sequence of the geometrical cross sections and top zone of columns.

The drawings of the $\mathrm{R} / \mathrm{C}$ sections at the base, at an intermediate height and on top, displayed in Figure 9, highlight an inner hole, where a spiral steel staircase to access the roof, and a conductor pipe are housed.
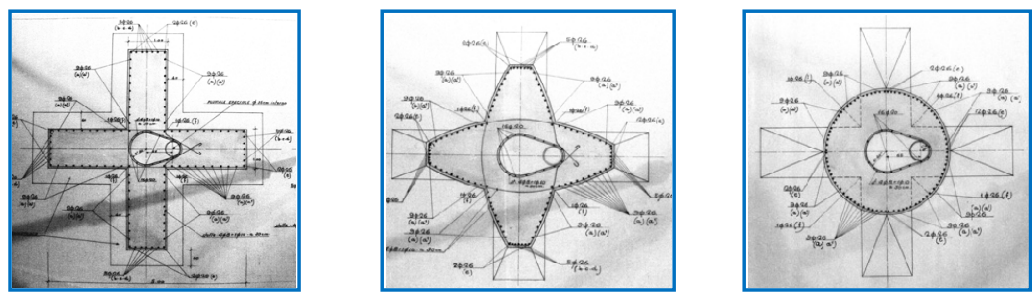

Figure 9: $\mathrm{R} / \mathrm{C}$ sections at the base, an intermediate height and the top of columns.

The geometry and the cross sections of the linear finite element model of columns, generated by SAP2000NL [2] too, are illustrated in Figure 10. The pseudo-acceleration design response spectrum adopted for the seismic analyses carried out at the basic design earthquake level (BDE, with a $10 \%$ probability of being exceeded over the reference period of 200 years fixed for the building, obtained by multiplying the assumed nominal structural life of 100 years by a coefficient of use equal to 2, as imposed by Standards [1] for strategic buildings) is plotted in Figure 11. A behaviour factor $q$ equal to 1.5 was selected to scale the ordinates of the corresponding elastic response spectrum, by considering the low-ductility inverted pendulum structural configuration of columns. The concrete used for columns and for the gallery slabs was " 680 "-type, with characteristic cubic compressive strength of $50 \mathrm{MPa}$. The reinforcing steel was "R50/60"-type, with yield stress of $370 \mathrm{MPa}$ and limit stress of $545 \mathrm{MPa}$. 
A confidence factor equal to 1.35 was adopted to reduce these nominal values, as well as those of the remaining mechanical parameters, in the verifications. This value corresponds to the lower knowledge level on existing buildings (L1) codified by Standards [1], and should be adopted when, as in this case, a detailed design documentation is available, but no direct experimental investigation is carried out on the structure.

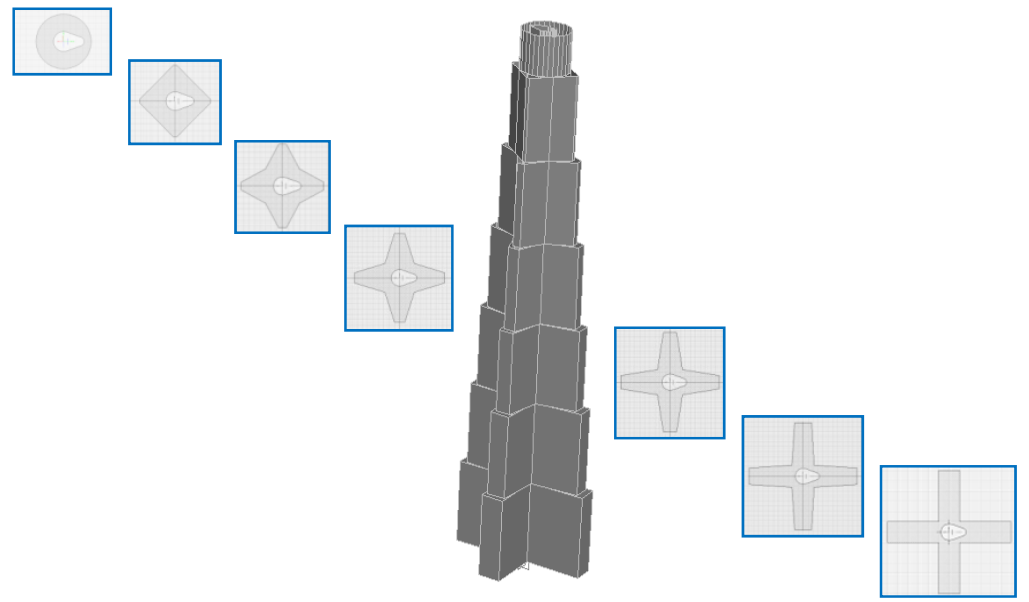

Figure 10: Geometry of the linear finite element model of columns.

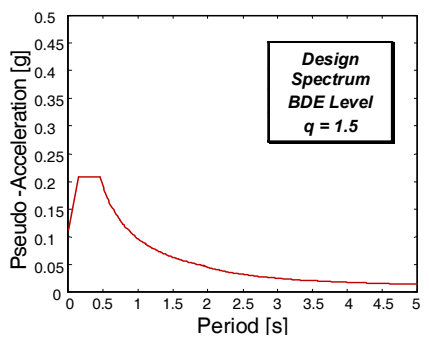

Figure 11: BDE-scaled pseudo-acceleration design response spectrum.

The results of the linear assessment analysis are synthesized in Figure 12, where the axial force-bending moment interaction domains of the sections shown in Figure 9, and the representative points of the maximum combined effects derived from the finite element computations, are plotted. These graphs highlight that the verification points are largely within the safety domain for all sections, and their distance from the borders of the domains is similar in the three cases, confirming that the columns have an approximately uniform resistance along the height, also according to the most recent normative verification criteria. 

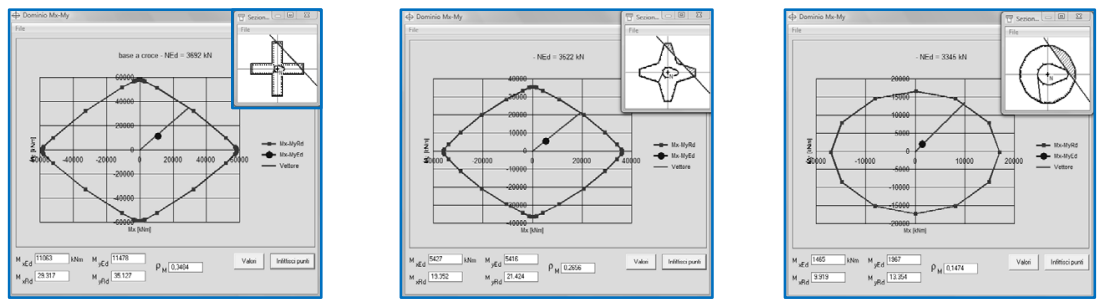

Figure 12: Axial force-bending moment domains of sections in Figure 9 and verification points derived from the analysis.

The second stage of the seismic assessment enquiry on the columns consisted in a non-classical pushover analysis, carried out by an integrally non-linear model, considering their uniform resistance original design conception [3]. The model was generated with ANSYS calculus program [4] and is made of a full mesh of solid octahedral "concrete" elements, with embedded steel reinforcing bars that can be freely oriented with respect to the global coordinate system. The geometry of the model, slightly simplified as compared to the linear model to avoid any possible critical elements for the development of the fullcracking/crushing analysis in the passage zones between the various sections along the height, is shown in Figure 13. Details on the values assigned to the mechanical parameters of the constituting materials in the non-linear field, as well as on the criteria followed in the development of the computational analysis, are reported in [3].
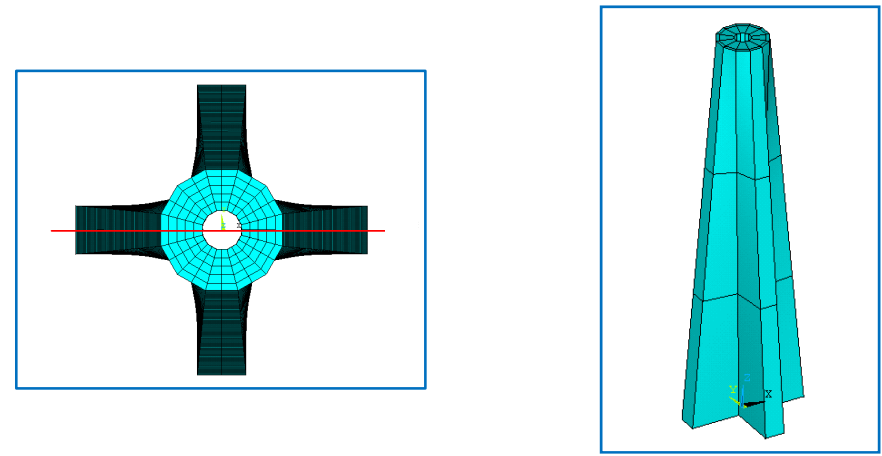

Figure 13: Geometry of the non-linear finite element model of columns.

The base shear-top displacement capacity curve obtained from the analysis is plotted in Figure 14. A median vertical section reproducing the cracked configuration of the model at the end of the last step of the pushover analysis, and two views orthogonal to the loading direction showing the distributions of the vertical component of normal stress and the axial stress in reinforcing bars, are displayed in Figure 15. 


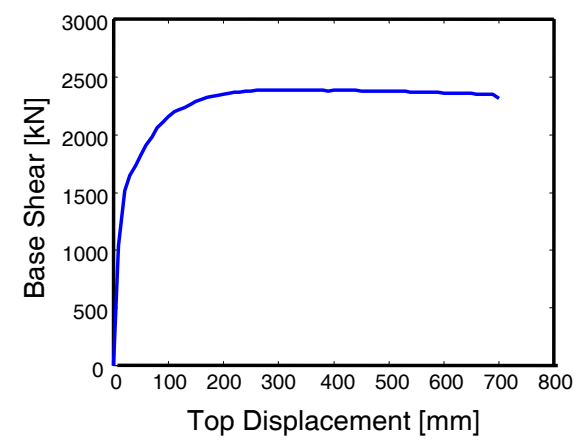

Figure 14: Pushover response curve.
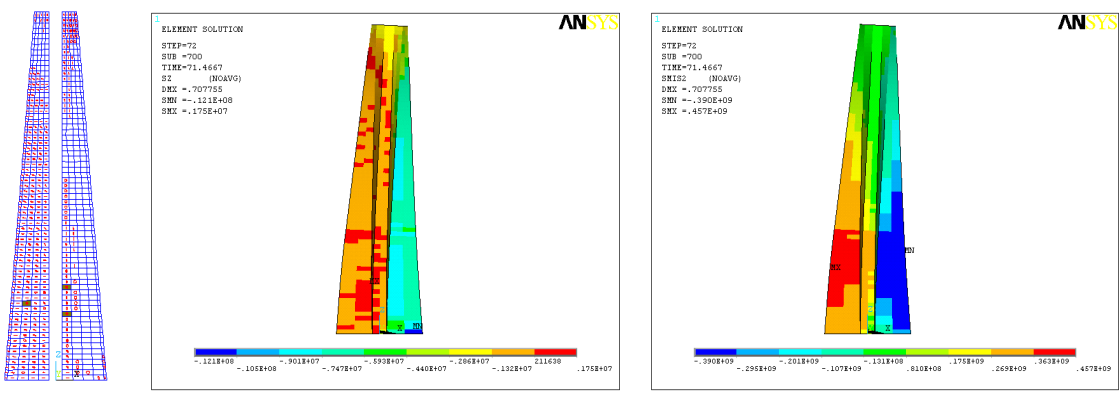

Figure 15: Cracked configuration, vertical normal stress distribution, and stress distribution in reinforcing bars at the end of the pushover analysis.

- The curve is rather linear up to around $1500 \mathrm{kN}$ (with top displacement of 20 $\mathrm{mm}$ and drift ratio of $0.1 \%$ ), that is up to around $60 \%$ of the maximum base shear, equal to $2390 \mathrm{kN}$; then, cracking begins to develop significantly in the elements situated on the tension side, and the curve visibly gets non-linear elastic;

- This second response phase goes on up to a force of $2200 \mathrm{kN}$, with a corresponding top displacement of $110 \mathrm{~mm}$ (drift ratio of $0.55 \%$ ), when the first plasticization of reinforcing bars occurs;

- The plasticization then increases, determining nearly a plateau zone extending from around $250 \mathrm{~mm}$ to around $450 \mathrm{~mm}$; the maximum shear force is reached for a displacement of $300 \mathrm{~mm}$ (drift ratio of $1.5 \%$ );

- A softening branch follows, featuring an accentuated strength degradation between $680 \mathrm{~mm}$ and $700 \mathrm{~mm}$, while it does not mean a sudden drop of strength in proximity to the numerical solution divergence point;

- Cracking extends rather uniformly over the tension side, whereas crushing is attained only in very few local elements situated around the inner hole (darkcoloured elements in the vertical section in Figure 15). This indicates that 
concrete is far from ultimate strength conditions on the compression side of the column at the last step of the analysis;

- This is confirmed by the distribution of the vertical components of normal stress, which shows maximum values no greater than $50 \%$ of the compressive strength of concrete, in the external fiber of base section;

- Plasticization of reinforcing bars is spread over $2 / 3$ of the height of the column.

The response curve highlights acceptable behavioural capacities of columns, with no damage for rather high base shear values, and reasonably good ductility resources. Furthermore, it confirms again the nearly uniform resistance characteristics of these members.

\section{Analysis of steel roof beams}

The verifications carried out on the steel roof beams showed the poorest resistance in terms of buckling of the web panels, as a consequence of the high slenderness of the webs. The finite element buckling analysis developed by the model displayed in Figure 16, generated with SAP2000NL, highlighted that the maximum lateral deformation is achieved in the fourth panel, with a corresponding buckling factor equal to 0.259 , that is, around one fourth of value 1 ensuring safety conditions.

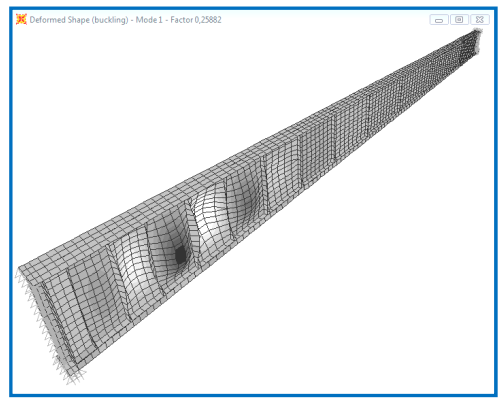

Figure 16: Deformed shape of the first buckling mode of steel beams.

The second through sixth modes correspond to the buckling of the adjacent panels, whereas the first two modes that involve global (lateral-torsional) instability are the seventh and eighth ones. Based on these results, a simple retrofit solution was proposed, which consists in strengthening the beams by a line of horizontal steel plates placed at mid-height of the cross sections, plus a diagonal plate positioned in the lower half of the panels that proved to be the most sensitive to buckling (the first 7 of 13, in the model represented in Figure 16), all welded to both sides of the web, as shown by the modified model in Figure 17. The first buckling factor in strengthened configuration grows to 1.33, guaranteeing a satisfactory safety margin with a low-impact intervention. 


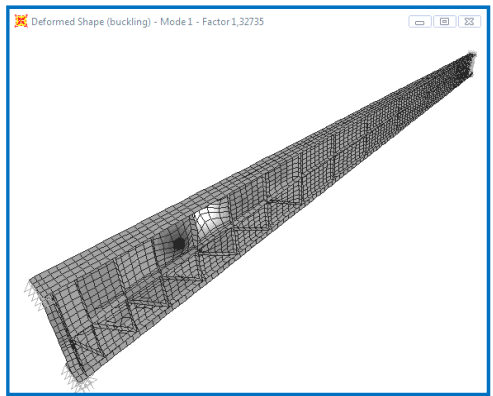

Figure 17: Deformed shape of the first buckling mode of steel beams after retrofit.

\section{Analysis of R/C gallery floors}

A series of symmetrical technical joints separates the R/C gallery floors in four identical angular zones and eight identical central zones. The most stressed members belong to the angular portions, whose finite element model is displayed in Figure 18. The model, generated again with SAP2000NL [2], includes flat slabs simulated by shell elements, ribs, and longitudinal, transversal, internal perimeter and cantilever beams reproduced by frame elements. The diagrams of the bending moment on the beams are also drawn in Figure 18.
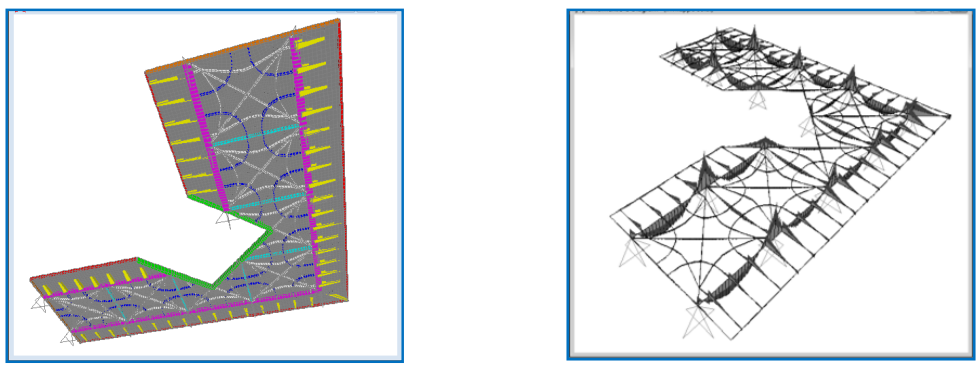

Figure 18: Finite element model of the gallery floors and bending moment diagrams on beams.

The equal tension stress lines on a slab field are plotted in superimposition to the plan of the ribs in Figure 19, showing a remarkable correlation between the computational solution and the original design of the $\mathrm{R} / \mathrm{C}$ members. The verifications carried out on the various elements always gave positive results for bending moments, while a lack of shear resistance was found in some terminal sections of the longitudinal and internal perimeter beams, as well as in the cantilever beams. A carbon fiber reinforced plastics (CFRP) U-jacket strengthening solution was proposed for these members, as illustrated in Figure 20 for the cantilever beams. One $0.165 \mathrm{~mm}$-thick sheet reinforcement was sufficient for all members, except for the longitudinal beams, where a double 
sheet was required. Here too, the interventions are characterized by a low architectural impact, and they are respectful of the historical and monumental value of the building.

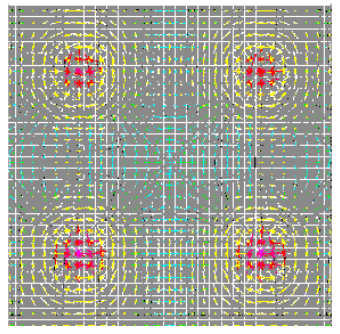

Figure 19: Tensile stress lines on a slab field and background draw of ribs.

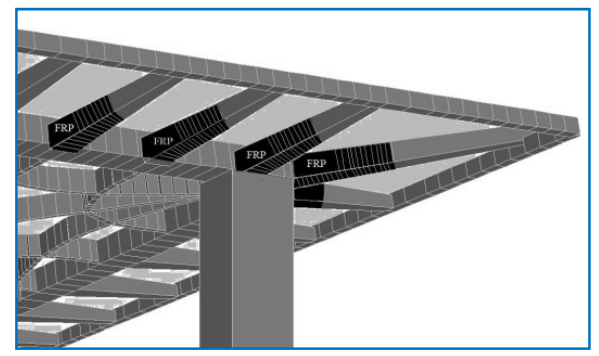

Figure 20: CFRP-based U-jacket strengthening of cantilever beams.

\section{Acknowledgements}

The study reported in this paper was financed by the Italian Ministry of Education, University and Research within the PRIN 2008 Project (Research Programme "Conceiving structures: engineering and architecture in Italy in the 1950 s and 1960s. A multi-disciplinary research"). The authors gratefully acknowledge this financial support.

\section{References}

[1] NTC (2008). New Technical Standards for constructions [in Italian]. G.U., Rome, Italy.

[2] CSI (2010). SAP2000NL. Structural Analysis Programs - Theoretical and Users Manual. Version No. 14.03, CSI, Berkeley, CA.

[3] Sorace S., Terenzi G. (2011). Non-linear finite element assessment analysis of a modern heritage structure. Complas XI - International Conference on Computational Plasticity, E. Onate and D.R.J. Owen, Eds., Barcelona, Spain, paper No. 116.

[4] Swanson Analysis System, Inc. (2010). ANSYS, Engineering Analysis System - Theory/Users' manual. Release 10.0, Canonsburg, PA. 